Especial: Profesores de Estudios Generales Investigan

I Sección: Historia, institucionalidad, prensa y creencias

\title{
Prodigia de Numa Pompilio a Emilio Paulo. \\ Lo sobrenatural ${ }^{\mathrm{i}}$
}

\author{
Emmanuel Mora Iglesias \\ Universidad de Costa Rica, Costa Rica \\ emorai1@yahoo.no \\ https://orcid.org/0000-0002-9880-1265
}

Recibido: 20 de diciembre de 2019

Aceptado: 5 de febrero de 2020

Resumen: Este artículo es un recuento de los diferentes prodigios y portentos registrados por el historiador roman Tito Livio desde su institucionalización (en el tiempo de los reyes romanos) hasta el fin de la III Guerra Macedónica. Hemos utilizado como una fuente importante los Prodigios de Julius Obsequens.

Palabras clave: Prodigium, Ostentum, Portentum, Historia Romana, Religión Romana.

\section{Prodigia from Numa Pompilius to Aemilius Paullus The Supernatural}

\section{(๑) $\odot \odot$}

La Revista Estudios es editada por la Universidad de Costa Rica y se distribuye bajo una Licencia Creative Commons Atribución-NoComercial-CompartirIgual 3.0 Costa Rica. Para más información envíe un mensaje a 


\section{Especial: Profesores de Estudios Generales Investigan}

Abstract: This article is an account of the prodigia and portenta registered by roman historian Titus Livius from it's institution (in the time of the Roman Kings) down to the end of the Third Macedonian War. We have used as an important source the Prodigies of Julius Obsequens.

Keywords: Prodigium, Ostentum, Portentum, History of Rome, Roman Religion.

\section{Introducción}

Las palabras prodigium, ostentum, portentum, designan todas ideas similares. Por prodigium entendemos un evento contario al curso natural de los hecho en la naturaleza, que sirve como una señal que la pax deorum se ha roto. Es también visto como un signo profético (Segura Munguía 2013: 602). Con el objeto de restaurar esa relación con los dioses (procuratio) los Pontífices (etimológicamente los que hacen puentes entre los hombres y los dioses) hacen ritos de expiación o de reparación. Ostentum es por otro lado un sinónimo de la palabra prodigio o presagio que es "todo lo que rebasa el orden natural y se muestra con asombro". (Segura Munguía 2013: 524). Portentum se puede definir como un suceso "revelado por algún fenómeno extraño o contrario a las leyes de la naturaleza. (Segura Munguía 2013: 579).ii

\section{Los Prodigia durante el Reino de Roma}

El Reino de Roma es establecido de acuerdo a la leyenda por Rómulo quien establece su enclave primario en la Colina Palatina (753 a.C.) A partir de este primer rey le sucederán diversos reyes cuya existencia se ha puesto en cuestionamiento y que se han visto como arquetipos de las distintas castas que

\section{(c) (1) 8 (2)}

La Revista Estudios es editada por la Universidad de Costa Rica y se distribuye bajo una Licencia Creative Commons Atribución-NoComercial-CompartirIgual 3.0 Costa Rica. Para más información envíe un mensaje a 


\section{Especial: Profesores de Estudios Generales Investigan}

surgen de las sociedades fundadas por los indoeuropeos (a saber la casta sacerdotal, la guerrera, la comerciante, etc). El rey que simboliza la casta sacerdotal es Numa Pompilio y nos dice precisamente Livio que fue este rey (que reina entre 716-674 a.C.) el que instituye la lectura de los prodigia. Numa Marcio, quien fue el primer pontífice romano y uno de los senadores, debía informar sobre ritos fúnebres y como calmar a los manes (sed iusta quoque funebria placandosque manes) sino también los prodigios con rayos provocados por Júpiter (quaeque prodigia fulminibus a love) y otros prodigios recogidos (quo visu missa susciperentur). (Liv. I.20-7.- 21-2.). Nos dice también que los asuntos religiosos eran ya del interés común.

Hacia el año 640 a.C., durante el reinado del rey Tulo Hostilio, Livio nos transmite un primer prodigio: ha caído una lluvia de piedras en el Monte Albano. Debemos recordar que el Monte Albano era un sitio asociado a la ciudad de Alba Longa (antigua cuna de Rómulo y Remo) y allí se ubicaba el templo de Júpiter Laciar, divinidad suprema protectora del Lacio. Al parecer hubo incredulidad con respecto a este fenómeno y se envía a alguien con el fin de que verifique el suceso y es cuando frente a él caen una lluvia de piedras parecidas a granizo. Continúa la fuente y nos dice que una voz se oye proveniente del bosque sagrado llamando a los albanos a no olvidar sus prácticas sacrificiales. Es a raíz de estos hechos que surgen los novendiales sacros que no son otra cosa que el ancestro de nuestros novenarios.

Ya al final de la época monárquica, durante el reinado de Tarquino el Soberbio, el último rey etrusco de Roma, se presenta un prodigio "terrible": Una serpiente se desliza desde una columna de madera del palacio real provocando pánico. Nos dice Livio que aunque para los prodigios se recurría a los adivinos etruscos (arúspices) se consultó el oráculo de Delfos ya que pareció que este prodigio tenía implicaciones para con la casa real (I.56). Este hecho pudo haber ocurrido en 513 o 512 a.C.ii

\section{(c) (i) (2)}

La Revista Estudios es editada por la Universidad de Costa Rica y se distribuye bajo una Licencia Creative Commons Atribución-NoComercial-CompartirIgual 3.0 Costa Rica. Para más información envíe un mensaje a revistaestudios.eeg@ucr.ac.cr. 
Especial: Profesores de Estudios Generales Investigan

\section{Cuadro 1. Prodigia registrados Reino de Roma (753-509 a.C.)}

\begin{tabular}{|c|c|c|c|c|c|c|}
\hline Año & Fuego & Agua & Monstrua & Otros & Expiación & Fuente \\
\hline 640 a.C. & & $\begin{array}{l}\text { Cae una } \\
\text { lluvia de } \\
\text { piedras en } \\
\text { el Monte } \\
\text { Albano. }\end{array}$ & & $\begin{array}{l}\text { Una voz en } \\
\text { el bosque } \\
\text { sagrado del } \\
\text { Monte } \\
\text { Albano se } \\
\text { oye. }\end{array}$ & $\begin{array}{l}\text { Se hacen } \\
\text { novendiales } \\
\text { por vez } \\
\text { primera. }\end{array}$ & Liv.I.31.4. \\
\hline $\begin{array}{lll}513 & \circ & 512 \\
\text { a.C. } & \end{array}$ & & & & $\begin{array}{l}\text { Serpiente } \\
\text { se desliza } \\
\text { desde una } \\
\text { columna de } \\
\text { madera en } \\
\text { el Palacio } \\
\text { Real y } \\
\text { provoca } \\
\text { pánico. }\end{array}$ & $\begin{array}{l}\text { Se envía a } \\
\text { consultar el } \\
\text { Oráculo de } \\
\text { Delfos. }\end{array}$ & Liv. I.56. \\
\hline
\end{tabular}

Como podemos observar en realidad Livio tan sólo nos transmite dos prodigios que acontecieron en esta época. Luego de la deposición de Tarquino el Soberbio comienza la época republicana (509 a.C.).

El mismo Livio admite en la pobre calidad de fuentes para esta época primera de la Historia de Roma:

"Hay tal incertidumbre en la fijación de las fechas, al ordenar las diversas fuentes de manera distinta la lista de magistrados, que no puede uno determinar de manera ordenada qué cónsules sucedieron a qué otros, ni qué acontecimientos ocurrieron en qué año, al quedar tan atrás no sólo los hechos, sino los mismos historiadores." II.21.4. ${ }^{\text {iv }}$

La cantidad de Prodigia transmitidos por Livio durante los primeros años de la República no arroja tampoco gran cantidad de datos. En 483 a.C. se nos informa sobre prodigios celestes inquietantes (Liv.Il.42.10). Veinte años después, en 463 a.C. se reporta otro fenómeno celeste: el cielo arde en distintos lugares.

\section{cc) (i) (2)}

La Revista Estudios es editada por la Universidad de Costa Rica y se distribuye bajo una Licencia Creative Commons Atribución-NoComercial-CompartirIgual 3.0 Costa Rica. Para más información envíe un mensaje a 


\section{Especial: Profesores de Estudios Generales Investigan}

¡Para paliar esto se decretan tres dias de fiestas! (Liv.Ill. 5-14). Debemos esperar hasta 428 a.C. para un nuevo reporte de prodigia: Una terrible sequía hizo que el ganado muriera de sarna, infección esta que luego se extiendió hacia los humanos y afectara la ciudad (de Roma). Se nos habla que augures falsos aprovecharon la situación al hacer dinero con la superstición de los demás pero que luego se hicieron ritos de expiación tan sólo siguiendo las formas tradicionales romanas. En efecto los profetas y los adivinos falsos no son un fenómeno exclusivo del mundo moderno...

En 399 a.C. por causas no claras un verano pestífero provoca grandes estragos para animales y humanos. El Senado ordenó ante esto que se consultasen los Libros Sibilinos y se decretó, por primera vez en la historia de Roma, la celebración de un lectisternio en el que Apolo, Latona, Diana, Hércules, Mercurio y Neptuno son propiciados durante ocho días. ${ }^{\vee}$ Es interesante observar la asociación del fenómeno festivo con el fenómeno resarcidor o reparador. Diez años después los conflictos con algunas ciudades de la dodecápolis etrusca provocaron que no hubiese adivivinos para su interpretación sobre los prodigios (recordemos que los arúspices eran sin excepción de origen etrusco). Finalmente no sólo se envia una misión al Oráculo de Delfos (el o $\mu \varphi \alpha \lambda o \varsigma$ u ombligo del mundo en la Antigüedad greco-romana) con el propósito de consultar a Apolo sobre la causa del portento. $E$ incluso se llega a secuestrar a un arúspice etrusco quien prescribe la forma correcta de expiación. (Liv.5.15.)

El saqueo de Roma llevado a cabo por los senones (pueblo celta) que habían irrumpido en el norte de Italia en 390 a.C. (387 a.C. de acuerdo a Polibio) destruye gran parte de los documentos relativos a la época de los reyes y de los primeros tiempos de la República. Livio se refiere en una digresión donde nos habla sobre la situación de la disponibilidad de las fuentes referentes a los primeros tiempos de la Historia de Roma en su propia época.

\section{(c) (i) (-)}

La Revista Estudios es editada por la Universidad de Costa Rica y se distribuye bajo una Licencia Creative Commons Atribución-NoComercial-CompartirIgual 3.0 Costa Rica. Para más información envíe un mensaje a revistaestudios.eeg@ucr.ac.cr. 


\section{Especial: Profesores de Estudios Generales Investigan}

"En cinco libros dejo consignada la historia de Roma desde su fundación hasta su toma por los galos: historia que abarca la época de los reyes, la de los cónsules y dictadores, los decenviros y los tribunos consulares; las guerras extranjeras, las disensiones intestinas; historia obscura, y que por su extraodinaria antigüedad aparece como los objetos que apenas se ven por su mucho alejamiento, y por la insuficiencia y escasez en aquellas misma épocas de documentos escritos, únicos guardianes fieles de los hecho pasados; y en fin, por la destrucción casi completa, en el incendio de la ciudad, de los registros de los pontífices y de otros monumentos públicos y particulares." (Liv.VI.1.) vi

\section{(c) (i) (2)}

La Revista Estudios es editada por la Universidad de Costa Rica y se distribuye bajo una Licencia Creative Commons Atribución-NoComercial-CompartirIgual 3.0 Costa Rica. Para más información envíe un mensaje a revistaestudios.eeg@ucr.ac.cr. 
Especial: Profesores de Estudios Generales Investigan

\section{Cuadro 2. Prodigia en los primeros tiempos de la República Romana (483-389 a.C)}

\begin{tabular}{|c|c|c|c|c|c|c|}
\hline Año & Fuego & Agua & Monstrua & Otros & Expiación & Fuente \\
\hline 483 a.C. & $\begin{array}{l}\text { Prodigios } \\
\text { celestes }\end{array}$ & & & & $\begin{array}{l}\text { Hay consulta pública y } \\
\text { privada sobre los prodigios } \\
\text { (consulta del vuelo de las } \\
\text { aves o de las entrañas). }\end{array}$ & Liv.II.42.10. \\
\hline 463 a.c. & $\begin{array}{l}\text { El cielo arde en } \\
\text { varios lugares. }\end{array}$ & & & $\begin{array}{l}\text { Se suceden varios } \\
\text { prodigios pero no se } \\
\text { especifica cuáles. }\end{array}$ & Se decretan 3 días de fiestas. & Liv.III.5.14. \\
\hline 428 a.C. & & & & $\begin{array}{l}\text { Ocurre una gran sequía } \\
\text { que provoca una gran } \\
\text { mortandad y una } \\
\text { epidemia de sarna. }\end{array}$ & $\begin{array}{l}\text { Se siguen los métodos } \\
\text { tradicionales romanos de } \\
\text { expiación. }\end{array}$ & Liv. IV.30. \\
\hline 399 a.c. & & & & $\begin{array}{l}\text { Verano pestífero } \\
\text { provoca una gran } \\
\text { mortandad. }\end{array}$ & $\begin{array}{l}\text { Se consultan los Libros } \\
\text { Sibilinos y se decreta un } \\
\text { lectisternio. }\end{array}$ & Liv.V.13. \\
\hline 389 a.C. & & $\begin{array}{l}\text { Aumento del } \\
\text { nivel de agua } \\
\text { del Lago Albano. }\end{array}$ & & & $\begin{array}{l}\text { Se envía una misión al } \\
\text { Oráculo de Delfos. } \\
\text { Se rapta a un arúspice } \\
\text { etrusco. Los tribunos } \\
\text { consulares deben renunciar } \\
\text { y se nombra a un interrex. }\end{array}$ & Liv.V.15. \\
\hline
\end{tabular}

Cabría esperar que luego del fatídico año para los romanos de 390 a.C. nos encontraríamos con un mayor número de fuentes pero no es así. Los datos de los prodigia que disponemos luego de esta época se refieren mayoritariamente a fenómenos como pestes y sequías.

\section{(c) (1) (-)}

La Revista Estudios es editada por la Universidad de Costa Rica y se distribuye bajo una Licencia Creative Commons Atribución-NoComercialCompartirIgual 3.0 Costa Rica. Para más información envíe un mensaje a revistaestudios.eeg@ucr.ac.cr. 
Especial: Profesores de Estudios Generales Investigan

\section{Cuadro 3. Prodigia de la época posterior al incendio de Roma por Breno (365-292 a.C.)}

\begin{tabular}{|c|c|c|c|c|c|c|}
\hline Año & Fuego & Agua & Monstrua & Otros & Expiación & Fuente \\
\hline $\begin{array}{l}365-364 \\
\text { a.C. }\end{array}$ & & $\begin{array}{l}\text { Desbordamiento } \\
\text { del Tíber }\end{array}$ & & Sequía & $\begin{array}{l}\text { Lectisternio } \\
\text { Ludi Scaenici }\end{array}$ & Liv.VII.1. \\
\hline 362 a.c. & & & & $\begin{array}{l}\text { Se hunde la mitad } \\
\text { del Foro. }\end{array}$ & $\begin{array}{l}\text { Los adivinos declaran que deben } \\
\text { sacrificar en el Foro aquello en lo que } \\
\text { residiese la fuerza romana. }\end{array}$ & \\
\hline 348 a.C. & & & & Peste & Lectisternio & Liv.VII.27 \\
\hline 344 a.c. & & $\begin{array}{l}\text { Cae una lluvia de } \\
\text { piedras que } \\
\text { oscurece el día. }\end{array}$ & & & $\begin{array}{l}\text { Se consultan los Libros Sibilinos y se } \\
\text { nombra un Dictador para que lleve a } \\
\text { cabo los sacrificios correspondientes. }\end{array}$ & Liv.VII.28 \\
\hline 340 a.C. & & & & $\begin{array}{l}\text { En Capua, durante } \\
\text { la I Guerra Samnita, } \\
\text { una figura } \\
\text { fantasmagórica se } \\
\text { aparece y pide un } \\
\text { sacrificio. }\end{array}$ & $\begin{array}{l}\text { Los arúspices confirman lo dicho por la } \\
\text { figura fantasmagórica. Un cónsul se } \\
\text { sacrifica voluntariamente. }\end{array}$ & Liv. VIII.6. \\
\hline 326 a.c. & & & & & $\begin{array}{l}\text { Lectisternio } \\
\text { Se propician las mismas divinidades. }\end{array}$ & \\
\hline 292 a.C. & & & & $\begin{array}{l}\text { Peste asola los } \\
\text { campos. }\end{array}$ & $\begin{array}{l}\text { Se consultan los Libros Sibilinos: } \\
\text { Esculapio se trae desde Epidauro } \\
\text { hasta Roma. }\end{array}$ & Liv.X.47. \\
\hline
\end{tabular}

\section{(c) (†)(2)}

La Revista Estudios es editada por la Universidad de Costa Rica y se distribuye bajo una Licencia Creative Commons Atribución-NoComercialCompartirIgual 3.0 Costa Rica. Para más información envíe un mensaje a revistaestudios.eeg@ucr.ac.cr. 


\section{Gráfico 1. Prodigia (640-292 a.C.)}

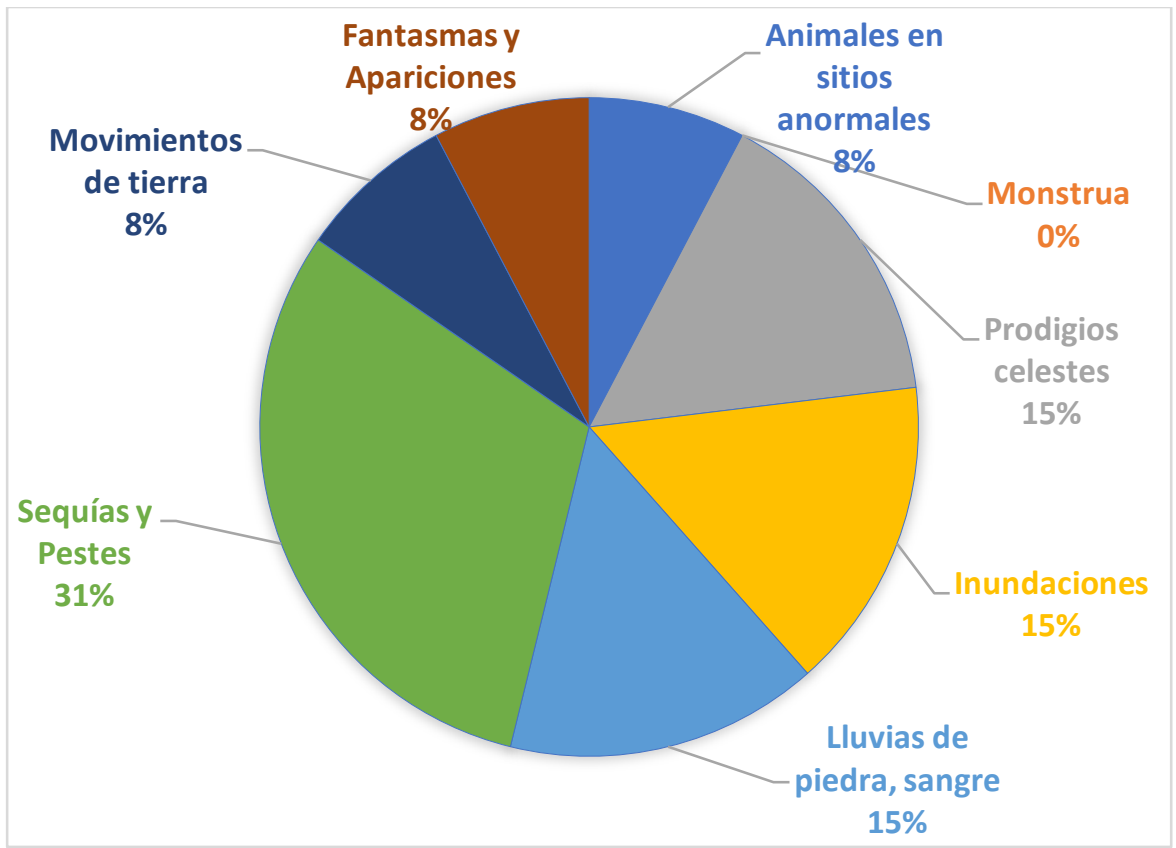

Fuente: Liv. I.31.a Liv. X.47.

Es notorio el predominio de fenómenos celestes de diverso tipo (aún más elocuente si sumamos las lluvias) y las sequías y las pestes. Por supuesto debemos tener en cuenta la gran cantidad de años de los que no tenemos datos al respecto.

También es de destacar que en esta época no se registran casos de animales o seres humanos con malformaciones, que mencionaremos más adelante, ni tampoco de golpes de rayos a edificios, murallas o seres vivos.

La casi totalidad del siglo III a.C. no está documentado ya que el libro XI se conserva tan sólo parcialmente y los libros del XII al XX se han perdido (cubrían

\section{(c) (i) (2)}

La Revista Estudios es editada por la Universidad de Costa Rica y se distribuye bajo una Licencia Creative Commons Atribución-NoComercial-CompartirIgual 3.0 Costa Rica. Para más información envíe un mensaje a revistaestudios.eeg@ucr.ac.cr. 


\section{Especial: Profesores de Estudios Generales Investigan}

los años de 284 a.C. a 220 a.C). Es por esta situación ya mencionada es que debemos esperar hasta el año 217 a.C. para encontrarnos prodigia precisamente durante el inicio de la Segunda Guerra Púnica, experiencia traumática para los romanos que sintieron que sus dominios iban a ser destruídos por una alianza entre distintos pueblos que deseaban sacudirse del dominio hegemónico romano o que buscaban reafirmar su hegemonía (el Imperio cartaginés, iberos, celtas).

Encontramos una gran cantidad de prodigia para estas fechas en un número mucho mayor que en los diez primeros libros de Livio. Hay que recalcar que en 216 a.C., año de la fatídica batalla de Canas, los prodigia son múltiples y elocuentes: corren rios de sangre, escudos sudan sangre, espigas de trigo caen con sangre, un rayo golpea a varios soldados... los sacrificios son múltiples y se busca también expiar los fenómenos a través de costosos regalos a imágenes de dioses en templos, se purifica la ciudad y se hacen votos solemnes.

\section{(c) (i) (2)}

La Revista Estudios es editada por la Universidad de Costa Rica y se distribuye bajo una Licencia Creative Commons Atribución-NoComercial-CompartirIgual 3.0 Costa Rica. Para más información envíe un mensaje a 
Especial: Profesores de Estudios Generales Investigan

\section{Cuadro 4. Prodigia registrados al inicio de la Segunda Guerra Púnica (217-215 a.C.)}

\begin{tabular}{|c|c|c|c|c|c|c|}
\hline Año & Fuego & Agua & Monstrua & Otros & Expiación & Fuente \\
\hline $\begin{array}{l}217 \\
\text { a.C. }\end{array}$ & $\begin{array}{l}\text { El templo de la } \\
\text { Esperanza en } \\
\text { el mercado de } \\
\text { hortalizas es } \\
\text { golpeado por } \\
\text { un rayo. }\end{array}$ & $\begin{array}{lr}\text { Hay una lluvia } \\
\text { de } \\
\text { cerca } \\
\text { Piceno. }\end{array}$ & & $\begin{array}{l}\text { Un niño de } 6 \text { meses de } \\
\text { edad, hijo de romanos } \\
\text { libres, grita "Yo triunfo" } \\
\text { en un mercado de Roma. } \\
\text { Un buey sube en el Foro } \\
\text { Boario al tercer piso de } \\
\text { una casa y se lanza desde } \\
\text { allí. } \\
\text { Una nave fantasma se ve } \\
\text { navegando en el cielo. } \\
\text { En Lanuvio la lanza de } \\
\text { Juno se mueve sola. } \\
\text { Un cuervo desciende } \\
\text { sobre el templo de Juno } \\
\text { en Lanuvio y se sienta en } \\
\text { una almohada. } \\
\text { En Amiterno se ven seres } \\
\text { de forma humana y } \\
\text { vestidos de blanco. } \\
\text { En Cerveteri se parten las } \\
\text { tablillas oraculares. } \\
\text { En la Galia un lobo quita a } \\
\text { un centinela su espada y } \\
\text { se va con ella. }\end{array}$ & $\begin{array}{l}\text { Se ordena a los } \\
\text { decénviros consultar los } \\
\text { Libros Sibilinos. } \\
\text { Se purifica la ciudad y se } \\
\text { sacrifican víctimas } \\
\text { mayores. } \\
\text { Por la lluvia de piedras } \\
\text { se decreta } \\
\text { novendiales sacrum. } \\
\text { En Lanuvio se hace una } \\
\text { importante ofrenda a } \\
\text { Juno en oro. } \\
\text { Las matronas dedican } \\
\text { una estatua de bronce a } \\
\text { Juno en el Aventino. } \\
\text { En Cerveteri, donde se } \\
\text { parten las tablillas } \\
\text { oraculares, se ordena } \\
\text { un lectisternio. } \\
\text { Se hace un servicio a la } \\
\text { intercensión a la } \\
\text { Fortuna. } \\
\text { En Roma se ordena un } \\
\text { lectisternio en honor a } \\
\text { la juventud. hacen rogativas } \\
\text { Se hersonales en el Templo }\end{array}$ & Liv.XXI.62. \\
\hline
\end{tabular}

La Revista Estudios es editada por la Universidad de Costa Rica y se distribuye bajo una Licencia Creative Commons Atribución-NoComercialCompartirIgual 3.0 Costa Rica. Para más información envíe un mensaje a revistaestudios.eeg@ucr.ac.cr. 
Especial: Profesores de Estudios Generales Investigan

\begin{tabular}{|c|c|c|c|c|c|c|}
\hline Año & Fuego & Agua & Monstrua & Otros & Expiación & Fuente \\
\hline & & & & & $\begin{array}{l}\text { de Hercúles. } \\
\text { Se sacrifican cinco } \\
\text { víctimas mayores al } \\
\text { Genio de Roma. } \\
\text { Se hacen votos para que } \\
\text { Roma siga en el mismo } \\
\text { estado por los próximos } \\
\text { diez años. }\end{array}$ & \\
\hline $\begin{array}{l}216 \\
\text { a.C. }\end{array}$ & $\begin{array}{l}\text { Un rayo } \\
\text { alcanza } \\
\text { varios } \\
\text { soldados. } \\
\text { El sol } \\
\text { disminuye su } \\
\text { tamaño. } \\
\text { El Sol lucha } \\
\text { con la Luna. } \\
\text { En Capua se ve } \\
\text { el cielo en } \\
\text { llamas. }\end{array}$ & $\begin{array}{l}\text { Llueven } \\
\text { piedras } \\
\text { ardientes del } \\
\text { cielo en } \\
\text { Palestrina. } \\
\text { En Cerveteri se } \\
\text { ven rios de } \\
\text { sangre } \\
\text { incluida la } \\
\text { Fuente de } \\
\text { Hércules. } \\
\text { En Capua se ve } \\
\text { a la Luna } \\
\text { cayendo en } \\
\text { medio de una } \\
\text { gran lluvia. }\end{array}$ & & $\begin{array}{l}\text { En Sicilia y Cerdeña } \\
\text { dardos de soldados se } \\
\text { cubren en llamas. } \\
\text { Dos escudos sudan } \\
\text { sangre. } \\
\text { Se ven escudos en el } \\
\text { cielo. } \\
\text { Se ven en Capena dos } \\
\text { lunas en el día. } \\
\text { En Anzio caen espigas con } \\
\text { sangre. } \\
\text { El Cielo se parte con una } \\
\text { luz resplandeciente. } \\
\text { Caen las } \\
\text { oraculares y una de ellas } \\
\text { tiene una inscripción a } \\
\text { Marte. } \\
\text { La imagen de Marte en la } \\
\text { Via Apia y las de los Lobos } \\
\text { sudan sangre. } \\
\text { Cabras se cubren de lana. } \\
\text { Una gallina se convierte }\end{array}$ & $\begin{array}{l}\text { Se hacen sacrificios de } \\
\text { victimas mayores y } \\
\text { menores. } \\
\text { Se hacen rogativas por } \\
\text { tres dias. } \\
\text { Se ordena consultar los } \\
\text { Libros Sibilinos y seguir } \\
\text { los que proceda. } \\
\text { Se da a Júpiter un rayo } \\
\text { de oro de } 50 \text { libras de } \\
\text { pesos. } \\
\text { Se dan regalos de plata } \\
\text { a Juno y Minerva. } \\
\text { Se hacen sacrificios de } \\
\text { victimas mayores a Juno } \\
\text { en el monte Aventino, a } \\
\text { Juno Salvadora en } \\
\text { Lanuvio. } \\
\text { Se celebra un } \\
\text { lectisternio. } \\
\text { Se dará un presente en } \\
\text { el Templo de Feronia. }\end{array}$ & Liv.XXII.57. \\
\hline
\end{tabular}

La Revista Estudios es editada por la Universidad de Costa Rica y se distribuye bajo una Licencia Creative Commons Atribución-NoComercialCompartirIgual 3.0 Costa Rica. Para más información envíe un mensaje a revistaestudios.eeg@ucr.ac.cr. 


\begin{tabular}{|c|c|c|c|c|c|c|}
\hline Año & Fuego & Agua & Monstrua & Otros & Expiación & Fuente \\
\hline & & & & $\begin{array}{l}\text { en gallo y un gallo en una } \\
\text { gallina. } \\
\text { Dos vestales cometen } \\
\text { estupro. }\end{array}$ & $\begin{array}{l}\text { Se sacrifican víctimas } \\
\text { mayores en el Foro de } \\
\text { Ardea y en el Templo de } \\
\text { Saturno. } \\
\text { Se envia una misión a } \\
\text { consultar el oráculo de } \\
\text { Delfos. } \\
\text { Se hacen sacrificios } \\
\text { inusuales. Se entierran } \\
\text { vivos a un hombre y una } \\
\text { mujer galos y a un } \\
\text { hombre y a una mujer } \\
\text { griegos. }\end{array}$ & \\
\hline $\begin{array}{l}215 \\
\text { a.C. }\end{array}$ & & $\begin{array}{l}\text { Una lluvia de } \\
\text { piedras cae } \\
\text { alrededor del } \\
\text { templo. } \\
\text { El mar parece } \\
\text { estar } \\
\text { llamas. }\end{array}$ & & $\begin{array}{l}\text { En Arienzo una vaca pare } \\
\text { un potro. } \\
\text { Estatuas en Lanuvio del } \\
\text { templo de Juno Sospita } \\
\text { sudan sangre. }\end{array}$ & $\begin{array}{l}\text { Por la lluvia se hace un } \\
\text { novendiales sacrum. } \\
\text { Otros presagios fueron } \\
\text { expiados de forma no } \\
\text { especificada. }\end{array}$ & Liv.XXIII.31. \\
\hline
\end{tabular}

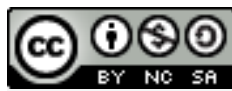

La Revista Estudios es editada por la Universidad de Costa Rica y se distribuye bajo una Licencia Creative Commons Atribución-NoComercialCompartirIgual 3.0 Costa Rica. Para más información envíe un mensaje a revistaestudios.eeg@ucr.ac.cr. 
Especial: Profesores de Estudios Generales Investigan

\section{Gráfico 2. Prodigia (217-215 a.C.)}

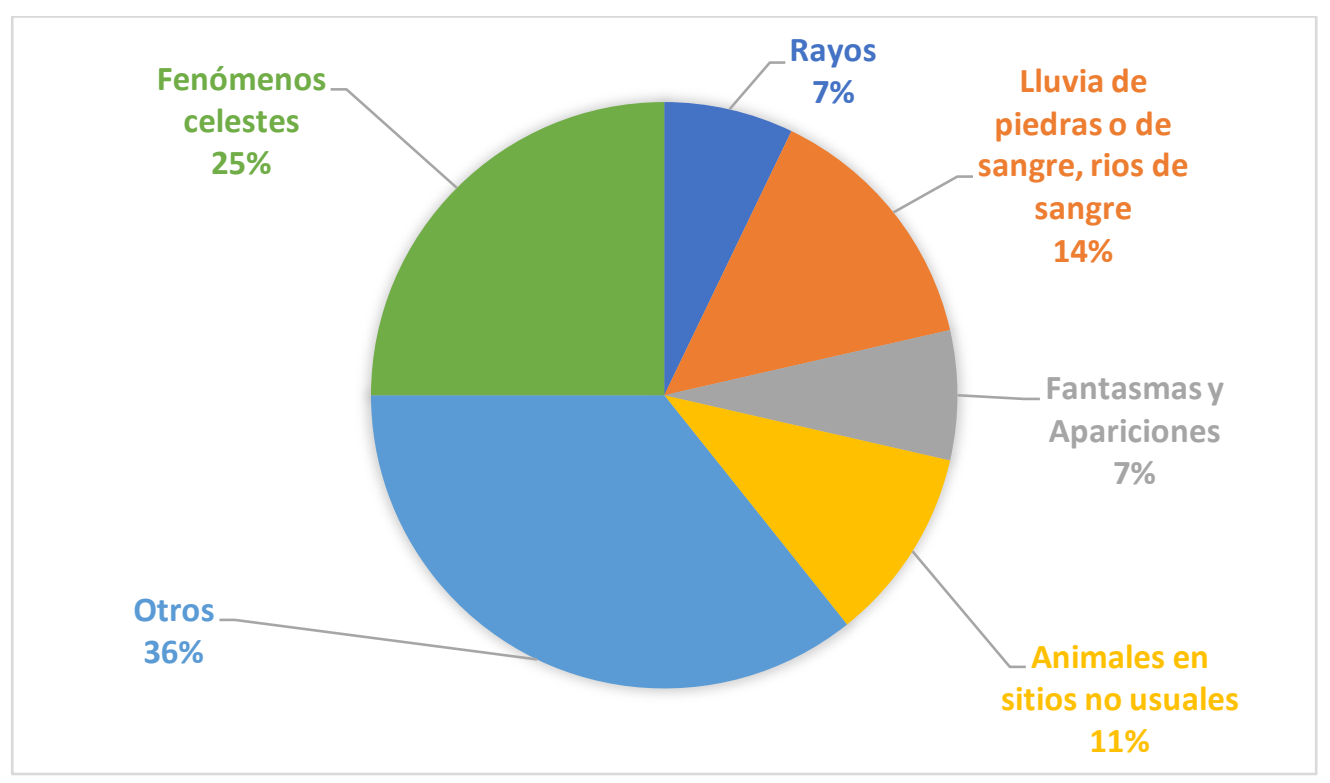

\section{Fuente: Liv.XXI.62 a XXIII.31}

No nos referiremos acá a la época posterior a 215 a.C. de acuerdo a Livio (que es de la más rica en prodigia y que es tema de otro articulo) pero si nos referiremos a los prodigia de acuerdo a Julius Obsequens quién es un desconocido, no mencionado en ninguno de los escritores de la Antiguedad. Se supone que fue un escritor pagano que escribió dentro de un Imperio Romano en proceso de cristianización y que tal vez vivió en el siglo IV d.C. Su obra (que cubre desde el año 190 a.C. al año ) es un Epítome de los Prodigia mencionados por Livio que se conserva en estado fragmentario.

Es hasta el período posterior a 215 a.C. en que aparecen Monstrua (singular monstrum, dicho sea en castellano monstruo) o sea animales o seres

\section{(c) (i) (-)}

La Revista Estudios es editada por la Universidad de Costa Rica y se distribuye bajo una Licencia Creative Commons Atribución-NoComercial-CompartirIgual 3.0 Costa Rica. Para más información envíe un mensaje a revistaestudios.eeg@ucr.ac.cr. 
Especial: Profesores de Estudios Generales Investigan

humanos con malformaciones que eran vistos como una muestra de la voluntad de los dioses (monstro, monstrare). Usamos ese término no en sentido peyorativo sino siguiendo el sentido de la palabra latina.

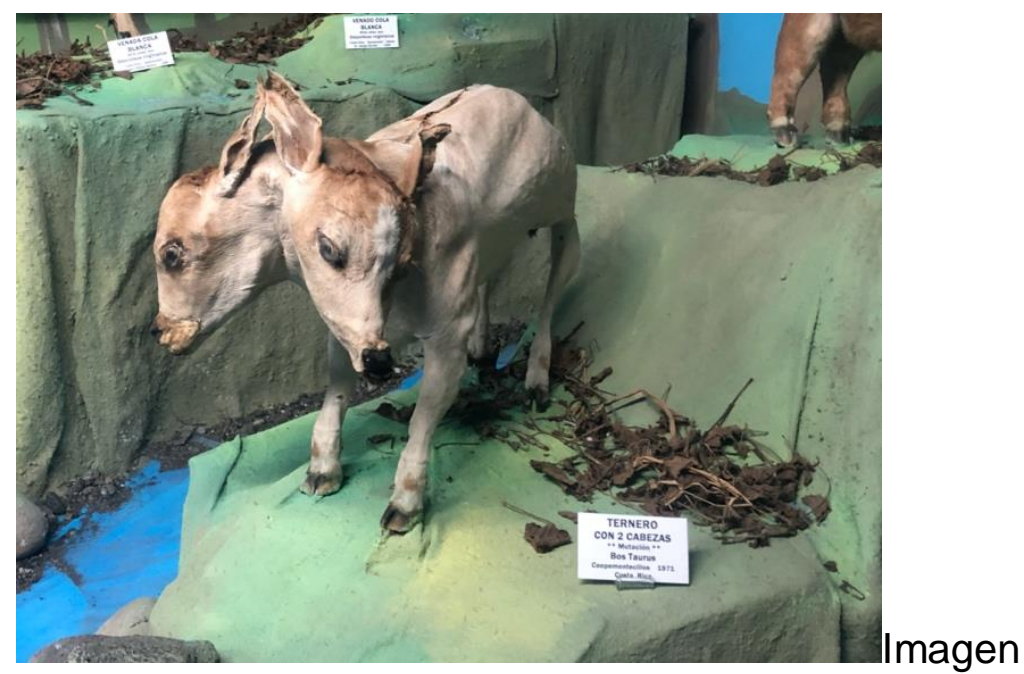

1.

Ternero con 2 Cabezas. Bos Taurus. Nacido en 1971.

Museo de La Salle. (Foto del autor)

"Vitulus biceps natus" Nació un ternero con dos cabezas. Jul. Obs.32.

\section{(C) $(\mathcal{Q} \Theta(-)$}

La Revista Estudios es editada por la Universidad de Costa Rica y se distribuye bajo una Licencia Creative Commons Atribución-NoComercial-CompartirIgual 3.0 Costa Rica. Para más información envíe un mensaje a revistaestudios.eeg@ucr.ac.cr. 
Especial: Profesores de Estudios Generales Investigan

Cuadro 4. Prodigia entre los años 190-171 a.C. de acuerdo a Julius Obsequens (sigue Livio).

\begin{tabular}{|c|c|c|c|c|c|c|}
\hline Año & Fuego & Agua & Monstruo & Otros & Expiación & Fuente \\
\hline 190 & $\begin{array}{l}\text { Templo de Juno Lucina } \\
\text { es alcanzado por un } \\
\text { rayo }\end{array}$ & $\begin{array}{l}\text { En Nursia llueve } \\
\text { torrencialmente } \\
\text { estadando despejado } \\
\text { el cielo y mueren dos } \\
\text { personas. } \\
\text { En Túsculo llovió } \\
\text { tierra. }\end{array}$ & & $\begin{array}{l}\text { En Reate pare una } \\
\text { mula. }\end{array}$ & $\begin{array}{l}\text { Rogativa por medio de } \\
\text { diez muchachos con } \\
\text { padre y madre vivos y } \\
\text { otras tantas muchachas. }\end{array}$ & $\begin{array}{l}\text { Obsequens.1. } \\
\text { (Liv.XXXVII,3,2- } \\
6 \text { ) }\end{array}$ \\
\hline 188 & & Lluvias de piedra. & & $\begin{array}{l}\text { Durante las horas } \\
\text { tercera y cuarta } \\
\text { comienza a hacerse } \\
\text { de noche. }\end{array}$ & $\begin{array}{l}\text { Se expían con un } \\
\text { novenario las lluvias de } \\
\text { piedra. }\end{array}$ & $\begin{array}{l}\text { Obsequens } 2 \\
\text { (Liv.XXXVIII,36, } \\
\text { 4) }\end{array}$ \\
\hline 186 & $\begin{array}{l}\text { Fuegos } \\
\text { surgen en muchos } \\
\text { lugares y chamuscan } \\
\text { la ropa de mucha } \\
\text { gente. El Tempo de } \\
\text { Júpiter en el Capitolio } \\
\text { fue alcanzado por un } \\
\text { rayo. }\end{array}$ & $\begin{array}{l}\text { Lluvias de piedra en el } \\
\text { Piceno. }\end{array}$ & $\begin{array}{ll}\text { En Umbría se } \\
\text { halla } & \text { un } \\
\text { hemafrodita. } & \end{array}$ & & $\begin{array}{l}\text { Se celebra un novenario } \\
\text { sacro por los fuegos } \\
\text { celestes. } \\
\text { Al hemafrodita se le da } \\
\text { muerte siguiendo } \\
\text { instrucciones de los } \\
\text { arúspices. }\end{array}$ & $\begin{array}{l}\text { Obsequens } 3 \\
\text { (Liv. XXXIX,22) }\end{array}$ \\
\hline 183 & & $\begin{array}{l}\text { Llueve sangre en la } \\
\text { explanada de Vulcano } \\
\text { por espacio de dos } \\
\text { días y en } \\
\text { expalanada la de } \\
\text { Concordia. }\end{array}$ & & $\begin{array}{l}\text { En Sicilia surge una } \\
\text { nueva isla en el } \\
\text { mar. }\end{array}$ & & $\begin{array}{l}\text { Obsequens } 4 \\
\text { (Liv. XXXIX } \\
\text { 46.5, } \\
\text { Liv.XXXIX, } \\
56,6 \text { ) }\end{array}$ \\
\hline 182 & $\begin{array}{l}\text { El Templo de Apolo } \\
\text { fue alcanzado por un }\end{array}$ & $\begin{array}{l}\text { Una terrible borrasca } \\
\text { derriba las estatuas de }\end{array}$ & $\begin{array}{l}\text { Nace un mulo } \\
\text { con tres patas }\end{array}$ & & & $\begin{array}{l}\text { Obsequens } 5 . \\
\text { (Liv. XL.2) }\end{array}$ \\
\hline
\end{tabular}

La Revista Estudios es editada por la Universidad de Costa Rica y se distribuye bajo una Licencia Creative Commons Atribución-NoComercial-

CompartirIgual 3.0 Costa Rica. Para más información envíe un mensaje a revistaestudios.eeg@ucr.ac.cr. 


\begin{tabular}{|c|c|c|c|c|c|c|}
\hline Año & Fuego & Agua & Monstruo & Otros & Expiación & Fuente \\
\hline & rayo. & $\begin{array}{l}\text { bronce en el Capitolio, } \\
\text { echa abajo las } \\
\text { estatuas junto con sus } \\
\text { pedestales en el Circo } \\
\text { Máxmo. }\end{array}$ & en Reate. & & & \\
\hline 181 & & $\begin{array}{l}\text { En las explanadas de } \\
\text { Vulcano y de la } \\
\text { Concordia } \\
\text { sangre. }\end{array}$ & & $\begin{array}{l}\text { Las lanzas de Marte } \\
\text { se movieron. } \\
\text { Una estatua de } \\
\text { Juno Sóspita } \\
\text { derramó lágrimas } \\
\text { en Lanuvio. } \\
\text { Libtiniavii tiene una } \\
\text { epidemia. }\end{array}$ & $\begin{array}{l}\text { Se hace una rogativa de } \\
\text { acuerdo con los Libros } \\
\text { ya que no había llovido } \\
\text { por seis meses. }\end{array}$ & $\begin{array}{l}\text { Obsequens } 6 \\
\text { (Liv.XL.19) }\end{array}$ \\
\hline 180 & N.D. & N.D. & N.D. & N.D. & N.D. & \\
\hline $\begin{array}{l}179 \\
y \\
178\end{array}$ & $\begin{array}{l}\text { Muchas estatuas son } \\
\text { destruídas por rayos } \\
\text { en Roma y sus } \\
\text { alrededores. }\end{array}$ & $\begin{array}{l}\text { A causa de continuas } \\
\text { tormentas algunas } \\
\text { estatuas se vienen } \\
\text { abajo. }\end{array}$ & & $\begin{array}{l}\text { En el lectisternio o } \\
\text { de Júpiter las } \\
\text { cabezas de los } \\
\text { dioses se dieron } \\
\text { vuelta durante un } \\
\text { temblor de tierra. } \\
\text { El plato con } \\
\text { cubiertos colocado } \\
\text { delante de Júpiter } \\
\text { se cayó. Unos } \\
\text { ratones roen las } \\
\text { aceitunas de una } \\
\text { mesa. }\end{array}$ & & $\begin{array}{l}\text { Obsequens } 7 \\
\text { (Liv. } \quad X L, 45 . \\
\text { Liv.XL, 59,7-8) }\end{array}$ \\
\hline 178 & $\begin{array}{l}\text { Incendio en los } \\
\text { alrededores del foro } \\
\text { que pasa sin dejar el }\end{array}$ & & & & & Obs.8 (Liv.XLI) \\
\hline
\end{tabular}

La Revista Estudios es editada por la Universidad de Costa Rica y se distribuye bajo una Licencia Creative Commons Atribución-NoComercialCompartirIgual 3.0 Costa Rica. Para más información envíe un mensaje a revistaestudios.eeg@ucr.ac.cr. 
ISSN 1659-3316

Febrero 2020

Mora Iglesias Emmanuel

Especial: Profesores de Estudios Generales Investigan

\begin{tabular}{|c|c|c|c|c|c|c|}
\hline Año & Fuego & Agua & Monstruo & Otros & Expiación & Fuente \\
\hline & $\begin{array}{l}\text { menor rastro del } \\
\text { Templo de Venus. } \\
\text { Se extingue el fuego } \\
\text { del santuario de Vesta. }\end{array}$ & & & & & \\
\hline 177 & N.D. viii & N.D. & N.D. & N.D. & N.D. & N.D. \\
\hline 176 & & & & $\begin{array}{l}\text { Un hígado se } \\
\text { descompone } \\
\text { cuando los } \\
\text { cónsules inmolan } \\
\text { las víctimas. }\end{array}$ & & $\begin{array}{l}\text { Obs.9 } \\
\text { (Liv.XLI,14). }\end{array}$ \\
\hline 175 & & & & $\begin{array}{l}\text { Seria plaga de } \\
\text { hombre y ganado. } \\
\text { Los cuerpos } \\
\text { quedan } \\
\text { desenterraos ya } \\
\text { que Libintina } \\
\text { estaba abrumada. } \\
\text { Los Celtíberos } \\
\text { fueron derrotados. }\end{array}$ & & $\begin{array}{l}\text { Obs. } 10 \text { (Liv. } \\
\text { XLI.21,5-7) }\end{array}$ \\
\hline 174 & N.D. & N.D. & N.D. & N.D. & N.D. & \\
\hline 173 & N.D. & N.D. & N.D. & N.D. & N.D. & \\
\hline 172 & N.D. & N.D. & N.D. & N.D. & N.D. & \\
\hline 171 & N.D. & N.D. & N.D. & N.D. & N.D. & \\
\hline
\end{tabular}

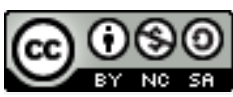

La Revista Estudios es editada por la Universidad de Costa Rica y se distribuye bajo una Licencia Creative Commons Atribución-NoComercial-

CompartirIgual 3.0 Costa Rica. Para más información envíe un mensaje a revistaestudios.eeg@ucr.ac.cr. 
Especial: Profesores de Estudios Generales Investigan

Durante esta época predominan los rayos y las lluvias de piedras y de sangre. Hay dos casos mencionados de monstrua, uno es el de un hemafrodita que nace y que los romanos dieron muerte casi inmediatamente (el método acostumbrado era sacarlos fuera de los limites de la ciudad, o arrojarlos al mar, y ejecutarlos). Por otra parte se menciona el nacimiento de un mulo con tres patas. Normalmente no se menciona la forma de expiación cuando nace un animal con polimelia (malformación en la cual un ser humano o un animal tiene más miembros de lo normal).

\section{Gráfico 3. Prodigia de acuerdo a Obsequens-Livio (190-171 a.C.)}

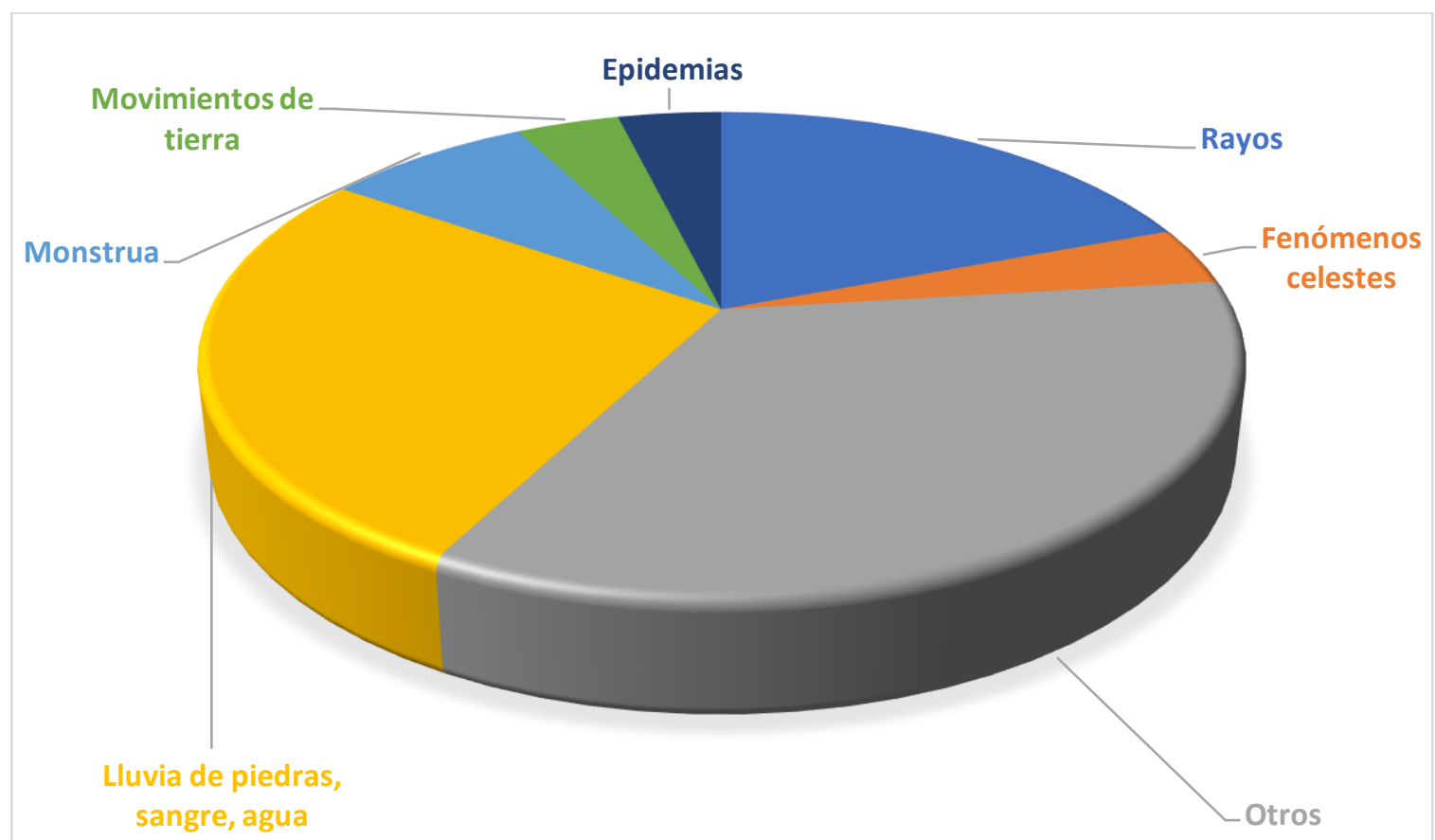

Fuente: Obsequens 1.-10.

\section{(c) (i) (2) (2)}

La Revista Estudios es editada por la Universidad de Costa Rica y se distribuye bajo una Licencia Creative Commons Atribución-NoComercial-CompartirIgual 3.0 Costa Rica. Para más información envíe un mensaje a revistaestudios.eeg@ucr.ac.cr. 
ISSN 1659-3316

Los prodigia que nos transmite Livio para los años 170-167 a.C., época de la III Guerra Macédonia (170-167 a.C.) son los últimos de su obra ya que los libros el XLVI al CXLII se han perdido (cubrían desde 165 a.C a 9 a.C). Por supuesto tenemos los recuentos de Julius Obsequens para estos años pero eso será tema de otro artículo. 
Especial: Profesores de Estudios Generales Investigan

\section{Cuadro 5. Prodigia durante la III Guerra Macedónica (170-167 a.C.)}

\begin{tabular}{|c|c|c|c|c|c|c|}
\hline Año & Fuego & Agua & Monstrua & Otros & Expiación & Fuente \\
\hline 170 & N.D. & N.D. & N.D. & N.D. & N.D. & \\
\hline 169 & $\begin{array}{l}\text { Se ve una } \\
\text { antorcha de } \\
\text { fuego en } \\
\text { Anagnia. } \\
\text { En Minturnas el } \\
\text { cielo parece en } \\
\text { llamas. }\end{array}$ & $\begin{array}{l}\text { En Rieti se hay } \\
\text { una lluvia de } \\
\text { piedras. } \\
\text { Lluvia de sangre } \\
\text { durante el día } \\
\text { en Roma. }\end{array}$ & $\begin{array}{l}\text { Una vaca habla (a } \\
\text { esa vaca se la } \\
\text { alimenta del erario } \\
\text { público). }\end{array}$ & $\begin{array}{l}\text { Apolo Ilora por } 3 \text { días y } 3 \\
\text { noches. (Cumas) } \\
\text { Una serpiente con tres } \\
\text { crestas es vista en el } \\
\text { Templo de la Fortuna por } \\
\text { varios. } \\
\text { Frente al Templo de } \\
\text { Fortuna Primigenia en } \\
\text { Roma nace una palmera. } \\
\text { Una palmera nace en el } \\
\text { interior de la casa de Tito } \\
\text { Marcio Figulo. } \\
\text { En la casa de Lucio Atreo } \\
\text { de Fregenellas arde una } \\
\text { lanza por dos horas pero } \\
\text { no se consume. }\end{array}$ & $\begin{array}{l}\text { Los decenviros consultan } \\
\text { los libros sibilinos con } \\
\text { relación a los prodigios } \\
\text { que interesan a la } \\
\text { República y se sacrifican } \\
\text { cuarenta víctimas } \\
\text { mayores, se ordenan } \\
\text { rogativas y sacrificios de } \\
\text { victimas por los } \\
\text { magistrados en todos los } \\
\text { templos. }\end{array}$ & Liv.XLIII.13. \\
\hline 168 & N.D. & N.D. & N.D. & N.D. & N.D. & \\
\hline 167 & 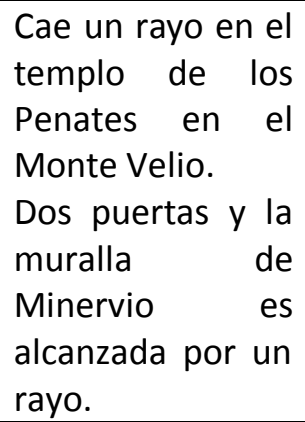 & $\begin{array}{l}\text { En Anagnia } \\
\text { Ilueve tierra. } \\
\text { En Calacia un } \\
\text { romano informa } \\
\text { que gotea } \\
\text { sangre en su } \\
\text { casa por tres } \\
\text { dias y dos } \\
\text { noches. }\end{array}$ & & & $\begin{array}{l}\text { Se ordena que los } \\
\text { decenviros consulten los } \\
\text { Libros Sibilinos y se } \\
\text { celebran rogativas en } \\
\text { todos los templos } \\
\text { durante un día y se } \\
\text { sacrifican } 50 \text { cabras. Se } \\
\text { hacen sacrificos de } \\
\text { víctimas y se purifica la }\end{array}$ & $\begin{array}{l}\text { Liv. XLV.16. } \\
5-7 . \\
\text { Obsq.11. }\end{array}$ \\
\hline
\end{tabular}

La Revista Estudios es editada por la Universidad de Costa Rica y se distribuye bajo una Licencia Creative Commons Atribución-NoComercialCompartirIgual 3.0 Costa Rica. Para más información envíe un mensaje a revistaestudios.eeg@ucr.ac.cr. 
Especial: Profesores de Estudios Generales Investigan

\begin{tabular}{|l|l|l|l|l|l|l|}
\hline Año & Fuego & Agua & Monstrua & Otros & Expiación \\
\hline $\begin{array}{l}\text { En Lanuvio se ve } \\
\text { un cometa en el } \\
\text { cielo. }\end{array}$ & & & & ciudad. \\
\hline
\end{tabular}

\section{Gráfico 4. Prodigia de acuerdo a Livio (170-167 a.C.)}

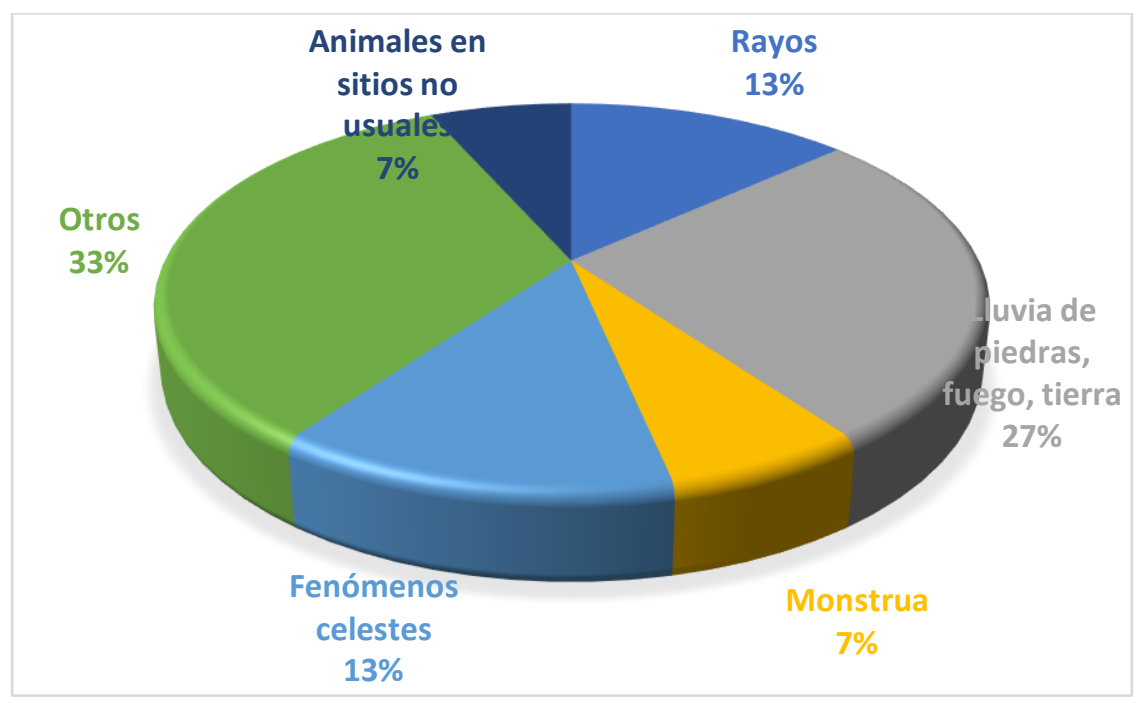

Fuente: Liv. XLII.13 a XLV.16.

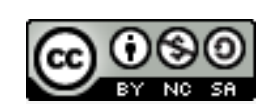

La Revista Estudios es editada por la Universidad de Costa Rica y se distribuye bajo una Licencia Creative Commons Atribución-NoComercialCompartirIgual 3.0 Costa Rica. Para más información envíe un mensaje a revistaestudios.eeg@ucr.ac.cr. 


\title{
Especial: Profesores de Estudios Generales Investigan
}

\section{Conclusiones}

Parece que en la misma época en que vivió Livio (la llamada Edad de Augusto) los presagios o prodigia ya no eran tomados con la misma seriedad que en los tiempos de la Monarquía y de la República Temprana o Media. Nos dice el mismo Livio que:

\begin{abstract}
"No ignoro que actualmente no se cree en los presagios que envían los dioses, y que por esta razón, ni se publican los prodigios ni se consignan en los anales. Pero al escribir la historia de remotos tiempos, mi ánimo se eleva naturalmente á lo antiguo, y no puedo considerar como indigno de figurar en mis anales hechos que la sabiduría de nuestros mayors creyó dignos de publicidad." Liv. XLIII.13. ${ }^{i x}$
\end{abstract}

Es de destacar que es gracias, no a la duda de Livio sobre estos fenómenos, sino a su apego a la tradición que estos datos han sido transmitidos por Livio o por el recopilador de fenómenos del Imperio Tardío Julius Obsequens.

Para concluir diremos que en términos generales podemos afirmar que de acuerdo a los datos analizados hay un predominio de fenómenos celestes de todo tipo, especialmente relacionados a la lluvia (lluvia de piedras, lluvia de sangre), a los rayos (rayos que golpean distintos sitios) y por último animales en sitios no usuales (normalmente animales silvestres que entran en el espacio urbano). También es de recalcar la aparición de siluetas o personajes fantasmagóricos. Con respecto a los monstrua son minoritarios -a diferencia de otros segmentos de tiempo que analizaremos en otra oportunidad. La percepción de lo sobrenatural en la Antigüedad comparada a la percepción sobre los mismos fenómenos en la época contemporánea será también tema de un próximo articulo.

\section{(c) (i) (9)}

La Revista Estudios es editada por la Universidad de Costa Rica y se distribuye bajo una Licencia Creative Commons Atribución-NoComercial-CompartirIgual 3.0 Costa Rica. Para más información envíe un mensaje a 


\section{Especial: Profesores de Estudios Generales Investigan}

\section{Fuentes}

Livio, T. 1985. Ab Urbe Condita. Libro XXII. (Rev. De Sebastián Mariner Bigorra). Madrid: Gredos.

Livio, T. 1975. Ab Urbe Condita. Libro XXV. (Rev. De Ana M. Martín Tordesillas). Madrid: Gredos.

Livio, T. 1944. Décadas de la Historia Romana. (Trad. Francisco Navarro Calvo). Buenos Aires: Joaquín Gil.

Livio T. 1888. Décadas de la Historia Romana. Tomo II. (Trad. Francisco Navarro y Calvo). Madrid: Sucesores de Hernando.

Livio, T. 1914. Décadas de la Historia Romana. Tomo IV.(Trad. Francisco Navarro y Calvo). Madrid: Sucesores de Hernando.

Livio T. 1889. Décadas de la Historia Romana. Tomo VII. (Trad. Francisco Navarro y Calvo). Madrid: Sucesores de Hernando.

Livio, T. 1990. Historia de Roma desde su Fundación. Libros I-III. (Trad. José Antonio Villar Vidal). Madrid: Gredos.

Livio, T. 1993. Historia de Roma desde su Fundación. Libros XXXI-XXXV. (Trad. José Antonio Villar Vidal). Madrid : Gredos.

Livio. 2011. Historia de Roma desde su Fundación. Libros I al X. (Trad. Antonio

DuarteSánchez).Recuperado de:

https://historicodigital.com/download/tito\%20livio\%20i.pdf

Livio. 2011. Historia de Roma desde su Fundación. Libros XXI al XXX. (Trad.

Antonio Duarte Sánchez). Recuperado de:

https://historicodigital.com/download/Tito\%20Livio\%20ll.pdf

Livy. 1991. Books XL-XLII. (With an English translation Evan Sage et al.) London: Loeb.

Livy. 2004. Summaries, Fragments Julius Obsequens. London: Loeb.

\section{(c) (i) (2) (2)}

La Revista Estudios es editada por la Universidad de Costa Rica y se distribuye bajo una Licencia Creative Commons Atribución-NoComercial-CompartirIgual 3.0 Costa Rica. Para más información envíe un mensaje a revistaestudios.eeg@ucr.ac.cr. 
Livio, T.et Obsequens, J. 1995. Períocas. Períocas de Oxirrinco. Fragementos. Libro de los Prodigios. Madrid: Gredos.

\section{Bibliografía}

Alemán, A . (2012). Precisiones Terminológicas sobre Ostentum en: Fundamenta luris. Recuperado de:

https://books.google.co.cr/books?id=luDIK98X1vYC\&pg=PA49\&lpg=PA49\&dq=An $\underline{a+A l e m a n+O s t e n t u m \& s o u r c e=b l \& o t s=k r f ~ Y l t K D J \& s i g=A C f U 3 U 1 ~ b D 9 X 1 v X X K B f N ~}$ zE1PgnyJln3w4Q\&hl=es\&sa=X\&ved=2ahUKEwj60LGh4q7nAhXQuVkKHf DCEw Q6AEwAXoECAoQAQ\#v=onepage\&q=Ana\%20Aleman\%200stentum\&f=false Bonfante, G y Bonfante, L. (2002). The Etruscan Language. Manchester: Manchester University Press.

Buck, C.D. (1904). A Grammar of Oscan and Umbrian: With a collection of inscriptions and a glossary. Boston: The Atheneum Press.

Dyer, T.H. (1868). The History of the Kings of Rome. London: Covent Garden. Hammond, NG.L. y Scullard, H.H. (1991). The Oxford Classical Dictionary. Oxford: Clarendon Press.

Linderski, J. 1995. "Roman Religion in Livy." In W. Schueller (ed.) Livius.Aspekte seines Werkes, Konstanz 1993: 608-625. Recuperado desde: https://www.academia.edu/33894166

Moure Casas, A. (1983) "Notas críticas sobre algunos pasajes de la IV década de T.Livio". En: Dialnet. 18.Cuadernos de Filología Clásica. Año 1983. Número 18: 217-223. Recuperado desde: https://dialnet.unirioja.es/ejemplar/137667 Pallotino, M. (1984). Etruscologia. Milano: Editore Ulrico Hoepli.

\section{(C) $(0 \otimes)$}

La Revista Estudios es editada por la Universidad de Costa Rica y se distribuye bajo una Licencia Creative Commons Atribución-NoComercial-CompartirIgual 3.0 Costa Rica. Para más información envíe un mensaje a revistaestudios.eeg@ucr.ac.cr. 
Rassmussen, S.W. (2000). Cicero's stand on Prodigies. A Non-existent Dilemma? En: Lorsch, R y Isager, J (eds.) Divinitation \& Portents in the Roman World. Gylling: Odense University Press.

Saglio, E et al. (1877-1919). Dictionaire des Antiquités Grecques et Romaines. Paris : Hachette.

Santangelo, F. (2013). Divination, Prediction and the End of the Roman Republic. Cambridge: Cambridge University Press.

Scullard, H.H. (1980). A History of the Roman World 753 to 146 B.C. London: Routledge.

Schulz, C. (2010) Divination and Diviners. En The Oxford Encyclopaedia of Ancient Greece and Rome. (1 ed,Vol. I, 527 pp.). Oxford: Oxford University Press.

Schulz, C. (2006). Religion in Republican Italy. Cambridge: Cambridge University Press.

Scullard, H.H.(1980). A History of the Roman World 753-146 B.C. London: Routledge.

Warrior, V. (2006). Roman Religion. Hong Kong: Cambridge University Press.

Warrior,V. (2002). Roman Religion. A Sourcebook. Newboyport MA: Focus Publishing.

\section{Notas}

\footnotetext{
'Parte de este articulo es parte de la investigación intitulada "Portentos y Prodigios en la Roma Republicana (s.II a.C.)" expuesta durante las III Jornadas de Investigación de la Sección de Historia de la Cultura de la Escuela de Estudios Generales de la Universidad de Costa Rica el 4 de Octubre de 2019. Hemos extendido el marco temporal de análisis presentado en las Jornadas para tener una perspectiva más amplia.

ii Para mayores detalles ver el excelente artículo de Alemán (2012).

iii De acuerdo a Dyer (1868): 425.

iv Livio, T (1990).

"Los lectisternios eran banquetes que se le hacían a los dioses en los que les se "invitaba" en forma de imágenes a compartir la cena en un lectus. Hammond (1991): 590.

vi Livio, T (1888).

vii En el Lucus Libitinae o bosque sagrado de Libitina en la colina del Esquilino en Roma había un templo dedicado a esta diosa asociada luego a Venus y relacionada a los funerales.

viii De acuerdo a Livy (1959):243 (nota de A.Schlesinger) los datos para este año están perdidos del Manuscrito de Julius Obsequens. Deben encontrarse en Livio XLI.13.1-3.

ix Livio, T (1889).
}

\section{() $(\otimes \odot$}

La Revista Estudios es editada por la Universidad de Costa Rica y se distribuye bajo una Licencia Creative Commons Atribución-NoComercial-CompartirIgual 3.0 Costa Rica. Para más información envíe un mensaje a 